\title{
Air Curtain Dust Removal Device Design and Dust Prevention Strategy in Heading Face
}

\author{
Xu Huang $(\mathbb{D}$ \\ College of Safety Science and Engineering, Liaoning Technical University, Fuxin 123099, China \\ Correspondence should be addressed to Xu Huang; huangxu@yeah.net
}

Received 9 August 2020; Revised 20 September 2020; Accepted 30 September 2020; Published 12 October 2020

Academic Editor: Marco Filippo Ferrotto

Copyright ( $\odot 2020 \mathrm{Xu}$ Huang. This is an open access article distributed under the Creative Commons Attribution License, which permits unrestricted use, distribution, and reproduction in any medium, provided the original work is properly cited.

\begin{abstract}
Dust protection is a safety guarantee of heading face. The previous model of air curtain research was ideal, and the dust removal effect was rarely studied in the actual dust-producing face. This paper presents a method of air curtain dust removal (ACDR) in the actual heading face. The author designed an air curtain dust removal device (ACDRD). The law of total dust concentration, respiratory dust concentration, and respiratory dust ratio is obtained. The minimum outlet airflow velocity is analyzed using the flat-plane injection theory. The effect of the exhaust fan placement on the dust removal effectiveness is examined. Research indicates the following: The airflow speed at the upper, left, and right sides of the $\cap$-shaped slot is $17.39 \mathrm{~m} / \mathrm{s}, 12.04 \mathrm{~m} / \mathrm{s}$, and $13.66 \mathrm{~m} / \mathrm{s}$, respectively. The minimum dust removal speed of the air curtain is $5.48 \mathrm{~m} / \mathrm{s}$. The total dust concentration is the highest in the spot of roadheader operator, and the concentration of respiratory dust decreases sharply within $20 \mathrm{~m}$. When the indentation air duct is $2.1 \mathrm{~m}$ away from the base plate, the dust-proof effect is better. The results can provide theoretical bases and methods for air curtain analysis of the heading face.
\end{abstract}

\section{Introduction}

Coal mine dust is one of the main hidden dangers restricting safe production. In China, $90 \%$ of underground coal mines face the problem of dust concentrations exceeding the limit [1]. The distribution of mine dust has the characteristics of wide spread in space and continuity in time. Normal ventilation system has not yet been formed in fully mechanized heading face. Dust concentration reaches up to $6000 \mathrm{mg} / \mathrm{s}^{3}$ without dust removal technologies [2]. After automatic high-pressure dust removal technology, the concentration of breathing dust at the driver's spot of the roadheader reaches 100 to $150 \mathrm{mg} / \mathrm{m}^{3}$ [3], which is more than 30 times the prescribed standard [4]. High dust concentration makes the working environment worse, threatens the health of workers, accelerates the wear of machinery and equipment, makes the visibility of space very low, and affects normal production [5].

Coal dust removal technology is divided into nine categories: dust removal, coal seam prehumidification dust removal, foam dust removal, water curtain dust removal, ventilation and dust removal, suction purification and dust removal, bonding dust removal, air curtain dust removal, and personal protection [6]. Due to technical conditions and the limitation of underground space area, underground excavation often uses wet dust removal methods, but those methods have the following disadvantages: water flow is easy to block, equipment and personnel work is not conducive, and water supply and drainage costs are increasing.

Air curtain dust removal (ACDR) technology has emerged in recent years [7]. It has the characteristics of transparent injection airflow, good sight of the driver, nonobstruction of transport, stable use, and so on $[8,9]$. Yucheng Li suggested that the air curtain spray airflow velocity should be 10 to $20 \mathrm{~m} / \mathrm{s}$, through the indentationextraction ventilation system, and the spray width should be 6 to $20 \mathrm{~mm}$ [10]. Liu Qiang analyzed the influence of radial pressure, axial pressure, and exhaust volume of the dust removal fan on the dust diffusion and pollution range of the air curtain device [11-13]. Wen Nie analyzed the effects of multidirectional air curtain dust removal on the fully mechanized heading face [14-16]. Hao Wang studied the 
effects of airflow quantity ratio parameters on air curtain dust suppression $[17,18]$. The operation of the ACDRD is carried out at the same time as the roadway excavation, in order to ensure good dust-proof effect, and the convenience of field operation should be considered. Only by the reasonable design of the ACDC system can it play its required role in the actual production. The airflow velocity of the air curtain fan, the structure size of the dust collector, and the dust pressure are the decisive factors influencing the dust removal effect. Previous researchers used numerical simulations and laboratory-like materials to study the effects of the width and distance of the air curtains in the dust removal unit on the dust removal effectiveness. However, the dust removal effect at spot of actual dust production in the subsurface is less studied. Subsurface space is limited, with multiple operation processes. Numerical simulation and similar material simulation research methods need to simplify the model; some of the factors are also ignored during model simplification process.

In this paper, an ACDRD is designed, and the minimum outlet airflow velocity of the air curtain device is analyzed using the flat-plane injection theory. Through the experiment of the dust concentration of the experimental heading face, the law of total dust concentration, respiratory dust concentration, and respiratory dust ratio is obtained. The effect of the exhaust fan placement on the dust removal effectiveness is examined. This study enriches the air curtain injection mechanism in a fully mechanized heading face.

\section{Methodology}

2.1. Layout of $A C D R D$. An experimental heading face was arranged in a coal mine. The width of the roadway is $5.2 \mathrm{~m}$, and the height is $3.8 \mathrm{~m}$. As shown in Figure 1, an S200MJ roadheader is used to cut coal. The anchor machine is used to support mechanical excavation. The heading face is equipped with an SGW-40T scraper conveyor and a DSP-1080/1000 conveyor belt. The external spraying device of the roadheader switches on during excavation work.

As shown in Figures 2 and 3, an ACDRD is installed in front of the roadheader driver. The jet outlet of the ACDRD is $7 \mathrm{~m}$ away from the heading face. The forcing fan is installed at the end of the duct to absorb fresh air. The injection box is installed on a roadheader. The forcing fan is placed on a special trailer and moves forward as the heading face is pushed forward.

After installing the ACDRD, the roadway is equipped with an air duct and an exhaust fan (as shown in Figure 1). The airflow quantity of the exhaust fan is larger than that of the forcing fan. The distance from the extraction of the pipe to the heading face is $2.5 \mathrm{~m}$. The pipe diameter is $600 \mathrm{~mm}$. Considering factors such as equipment size, height of personnel, and height of air duct suspension, $2.1 \mathrm{~m}$ is used as the lower limit height of the air duct, and the upper limit height of the air duct suspension is $3.0 \mathrm{~m}$.

2.2. Air Curtain Structure and Parameters. ACDRD is the most important part of the dust removal system. It should occupy less space, with flexible and good operation, to avoid

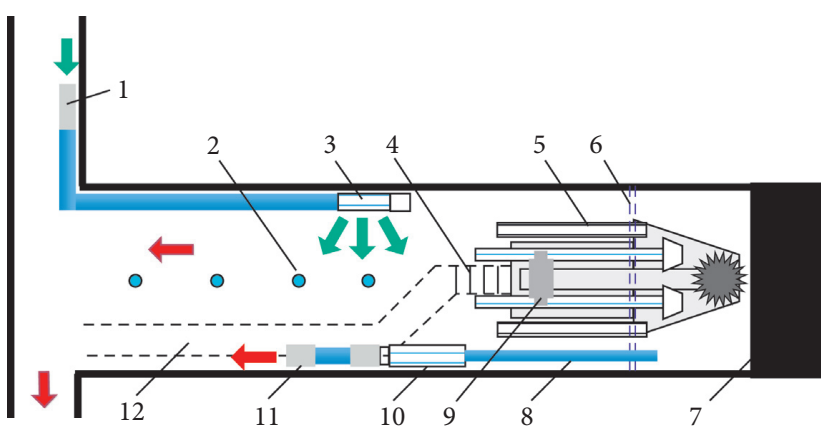

FIGURE 1: Roadway layout after installing ACDRD. (1) Forcing fan; (2) dust measuring spots; (3) dust removal device; (4) reproduced bridge; (5) S200MJ roadheader; (6) air curtain; (7) heading face; (8) air duct; (9) ACDRD; (10) dust collector; (11) exhaust fan; (12) belt conveyor.

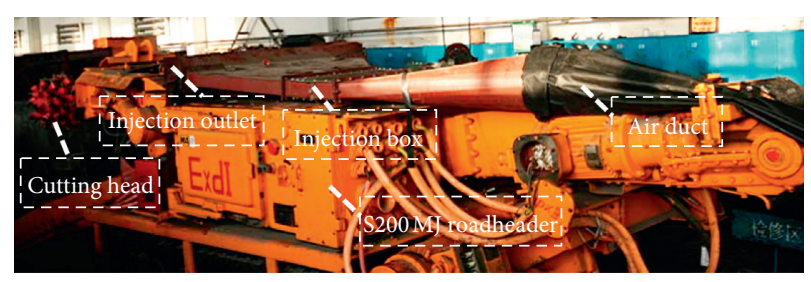

FIgURE 2: The location of the ACDRD on the roadheader.

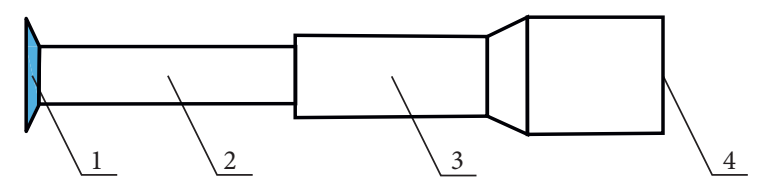

FIgURe 3: Profile of ACDRD. (1) Injection outlet; (2) injection box; (3) air duct; (4) forcing fan inlet.

hindering the normal line of sight of the driver. ACDRD is divided into forcing module and exhaust module. The forcing module includes forcing fan, air curtain ejection device, and air curtain fan. As shown in Figures 4-6, the air curtain ejection device mainly uses a $\nabla$-shaped injection box or a $\cap$-shaped narrow slot injection cavity to eject the airflow. At the same time, airflow velocity is adjusted by changing the slit width and the specific structure of the baffle. The exhaust module includes an exhaust fan and a dust removal fan. All components comply with relevant regulations to avoid safety hazards or deterioration of working conditions.

According to the shape and layout position parameters of the S200MJ roadheader, the main design parameters of the ACDRD are shown in Table 1.

2.3. Test Site Layout and Dust Collection Device. According to the actual situation of the experimental heading face, the measurement layout follows the "Sampling Specifications for the Monitoring of Hazardous Substances in the Air of Workplaces" [19], "Determination of Dust 


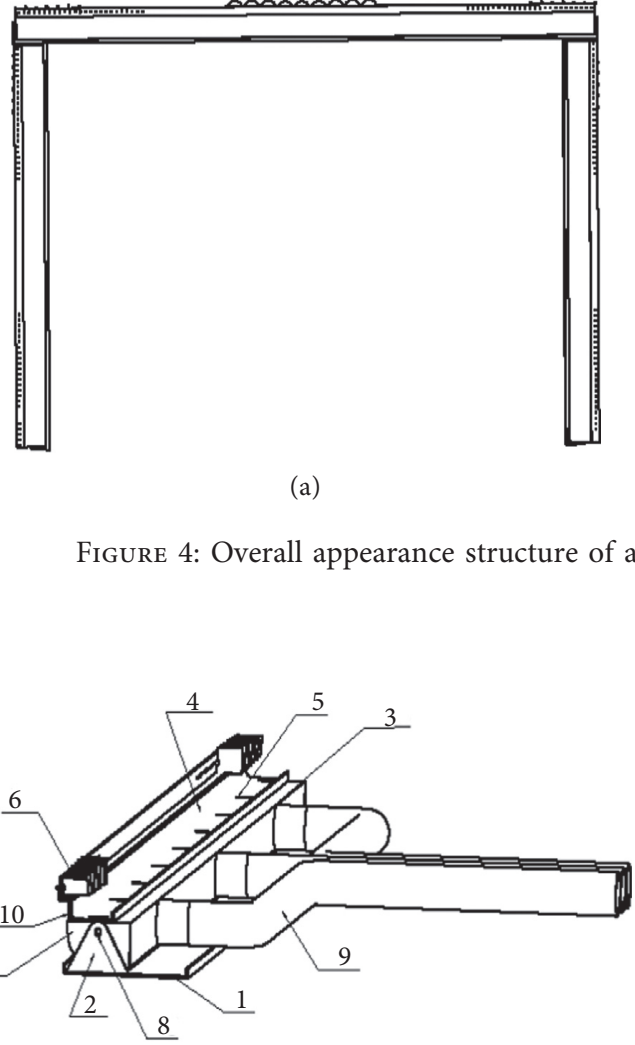

(a)

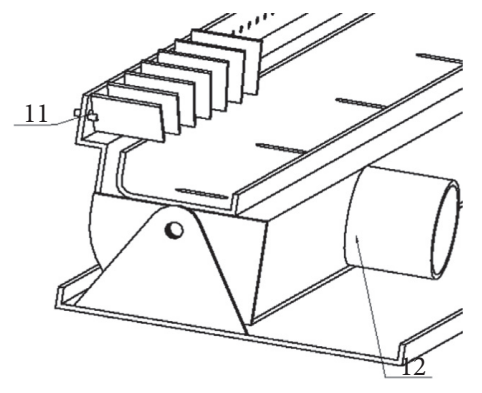

(b)

Figure 5: Injection box structure of air curtain forcing device. (1) Bottom plate; (2) support piece; (3) forcing cavity fixed plate; (4) movable injection cavity top plate; (5) adjusting nut; (6) air guide piece; (7) injection cavity; (8) rotary support shaft; (9) air duct; (10) injection nozzle; (11) air guide blade adjustment shaft; (12) air supply nozzle.

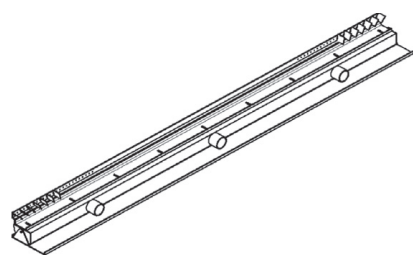

(a)

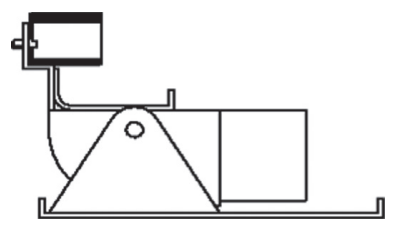

(b)

FIGURE 6: Appearance structure of upper injection box: (a) schematic diagram of the upper injection box; (b) left view of the upper injection box.

TABLE 1: Main parameters of the ACDRD.

\begin{tabular}{lcc}
\hline Content & Unit & Parameter \\
\hline Injection box height & $\mathrm{mm}$ & $\mathrm{mm}$ \\
Length of the upper injection cavities connected to the outlet & $\mathrm{mm}$ & -3200 \\
Distance between the upper vent and outlet & $\mathrm{mm}$ & - \\
Number of inlets on the left/right side of the injection chamber & $\mathrm{mm}$ & 3840 \\
Distance to the left/right injection chamber of outlet & $\mathrm{mm}$ \\
Number of air inlets on the left/right side of the injection cavity & - & 350 \\
Distance between the injection cavity on the left/right side connected to the outlet & $\mathrm{mm}$ \\
Adjustable width of slits & $0-22$ \\
Number of air bezels installed on both sides of the injection box & $25 \times 2$ \\
Spacing of the pores on both sides of the injection tank & 20 \\
\hline
\end{tabular}


Concentration and Dispersion" [20], "Determination of Dust in Workplace Air Part One: Total Dust Concentration" [21], and "Determination of Dust in Workplace Air Part Two: Respiratory Dust Concentration" [22]. The exact arrangement of measuring spots can be shown in Table 2 .

The AKFC-92A mine dust sampler (shown in Figure 7) is used for spot sampling tests. Part of the dust-laden air is extracted; all dust particles are captured on the filter membrane, and they gradually accumulate. After sampling, the total dust mass in the unit volume can be calculated from the increase in the weight of the membrane.

When measuring the concentration of inhalable dust, the separator captures larger particles onto a glass plate coated with silicone oil. Smaller particles can be captured by the cavity around the plate and retained on the membrane. After sampling, the mass of breathable dust per unit volume can be calculated from the increase in the weight of the membrane.

\section{Results and Discussion}

3.1. Minimum Dust Removal Airflow Velocity. We choose a reasonable amount of airflow for the air curtain to reduce the impact on the working surface. The airflow of the ACDRD reaches the rock mass around the roadway and acts as a dust blocker. The airflow speed at the end of the air curtain is greater than the roadway. After being emitted from the air curtain, the airflow gradually decays. The airflow speed at the injection end must be ensured to remove the dust in the air curtain.

As shown in Figure 8, the overall structure of the injection is complex. Fluid characteristics are less affected by the external region near the injection outlet, which is the core area of the injection outlet. The initial segment $\left(L_{0}\right)$ extends from the injection source to the end of the core area. Farther away from the initial area is the body part, where the injection fluid is fully mixed with the external area. There is a shorter transition part between the initial part and the body parts. The transition part is negligible, so the injection is mainly divided into the initial part and the body part.

By experiments, Alberston obtained a general expression attenuation formula for the maximum axial average velocity of the injection [24]:

$$
\frac{u_{m}}{u_{0}}=\frac{C_{01}}{\sqrt{x / b_{0}}},
$$

where $C_{01}=3.12-3.78$.

As different scholars use different reference coefficients, the experiment of air curtain injection slit was carried out, and the coefficient of semiexpansion thickness was obtained. The airflow speed on the upper and right sides is tested. The airflow speed on the left side is the same as that on the right side. The test data are displayed in Table 3. [25]:

We fit the test data according to the following equation

$$
u_{m} \propto \frac{1}{\sqrt{x}} .
$$

The attenuation coefficient of the upper axial speed is 4.25 , and the decay coefficient of the right axial velocity is
3.63. The axial mean speed attenuation coefficient on the right side is within the theoretical range. The attenuation coefficient of the above average axial speed is greater than the theoretical value. Considering the measurement position and measurement accuracy of airflow speed, it is acceptable to set a value greater than the theoretical value.

The maximum time average speed decay formulas on the upper and both sides are, respectively,

$$
\begin{gathered}
u_{0 t}=\frac{u_{m t} \sqrt{x_{t} / b_{g}}}{4.25}, \\
u_{0 l-r}=\frac{u_{m l-r} \sqrt{x_{l-r} / b_{g}}}{3.63},
\end{gathered}
$$

where $u_{0 t}, u_{0 l}, u_{0 r}$ represent the outflow speed on the upper side, left side, and right side, $\mathrm{m} / \mathrm{s} ; u_{m t}, u_{m l}, u_{m r}$ represent the maximum axial average speed at the axial distance of the upper side, left side, and right side, that is, the lowest dustremoval airflow speed at the end of the airflow, which is $5.48 \mathrm{~m} / \mathrm{s} ; x_{t}, x_{l}, x_{r}$ represent the distances of the upper side, left side, and right side wind outflow nozzles from the surrounding roadways, which are, respectively, $2.0,0.7$, and $0.9 \mathrm{~m}$; and $b_{s}$ is the slit that can be adjusted to a half thickness of the maximum width, with a value of $0.011 \mathrm{~m}$ (the maximum width of the injection outlet can be $22 \mathrm{~mm}$, which meets the maximum airflow demand).

Separately calculated, $u_{0 t}=17.39 \mathrm{~m} / \mathrm{s}, \quad u_{0 l}=12.04 \mathrm{~m} / \mathrm{s}$, and $u_{0 r}=13.66 \mathrm{~m} / \mathrm{s}$. The upper, left, and right slots observe the effect of the ACDR at the lowest airflow speed of $2.04 \mathrm{~m} /$ s. We use the following formula to obtain $Q_{t}, Q_{l}$, and $Q_{r}$ :

$$
Q=A u_{0}
$$

where $Q$ is the airflow at injection outlet, $\mathrm{m}^{3} / \mathrm{s} ; A$ is the area of the exits on the upper, left, and right sides, $\mathrm{m}^{2}$. Separately obtained, $Q_{u}=0.022 \times(3.6+0.12 \times 2) \times 17.39=1.47 \mathrm{~m}^{3} / \mathrm{s} ; Q_{l}=$ $0.022 \times 1.8 \times 12.04=0.48 \mathrm{~m}^{3} / \mathrm{s} ; \quad$ and $\quad Q_{r}=0.022 \times 1.8 \times$ $13.66=0.54 \mathrm{~m}^{3} / \mathrm{s}$. The required airflow quantity of the $\mathrm{ACDRD}$ is $Q_{t}=Q_{u}+Q_{l}+Q_{r}=1.47+0.48+0.54=2.49 \mathrm{~m}^{3} /$ $\mathrm{s}=149.4 \mathrm{~m}^{3} / \mathrm{min}$.

The actual airflow quantity of the outlet of the extraction network is $1224.4 \mathrm{~m}^{3} / \mathrm{min}$, with some airflow being used for the heading face and the rest being provided for the ACDR. Therefore, the actual airflow quantity of the heading face is $1075 \mathrm{~m}^{3} / \mathrm{min}$. Theoretically, the airflow quantity should be greater than $1075 \mathrm{~m}^{3} / \mathrm{min}$, so that the outflow air will be deflected to the heading face.

Figure 9 shows the effect of the air curtain. Plastic ribbon is tied at the outlet of the air curtain to facilitate observation of airflow direction and speed. After the ACDRD is installed in the experimental roadway, the distance between the outlet of the air curtain and the roadway walls on both sides is about $1.3 \mathrm{~m}$. At this time, the airflow speed of the air curtain is about $3 \mathrm{~m} / \mathrm{s}$, which fully meets the requirements of the ACDRD. The airflow speed at a position $2.5 \mathrm{~m}$ away from the jet exit of the air curtain is measured. The airflow speed is generally around $2 \mathrm{~m} / \mathrm{s}$, indicating that this device can still form an effective air curtain in a wide roadway. 
TABLE 2: Arrangement of measuring spots.

\begin{tabular}{lccccccccccccccc}
\hline \multirow{2}{*}{ Test item } & \multicolumn{11}{c}{ Distance from measurement spot to heading face (m) } \\
& 14.3 & 20 & 25 & 35 & 40 & 50 & 60 & 65 & 70 & 80 & 90 & 95 & 100 & 110 & 120 \\
\hline Total dust concentration & $\sqrt{ }$ & $\sqrt{ }$ & $\sqrt{ }$ & $\sqrt{ }$ & $\sqrt{ }$ & $\sqrt{ }$ & $\sqrt{ }$ & - & $\sqrt{ }$ & $\sqrt{ }$ & $\sqrt{ }$ & - & $\sqrt{ }$ & $\sqrt{ }$ & $\sqrt{ }$ \\
Respiratory dust concentration & $\sqrt{ }$ & $\sqrt{ }$ & $\sqrt{ }$ & $\sqrt{ }$ & $\sqrt{ }$ & $\sqrt{ }$ & $\sqrt{ }$ & - & $\sqrt{ }$ & $\sqrt{ }$ & $\sqrt{ }$ & - & $\sqrt{ }$ & $\sqrt{ }$ & $\sqrt{ }$ \\
\hline
\end{tabular}

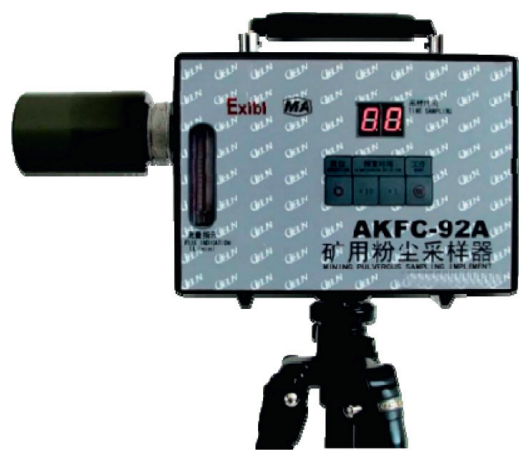

Figure 7: AKFC-92A mine dust sampler.

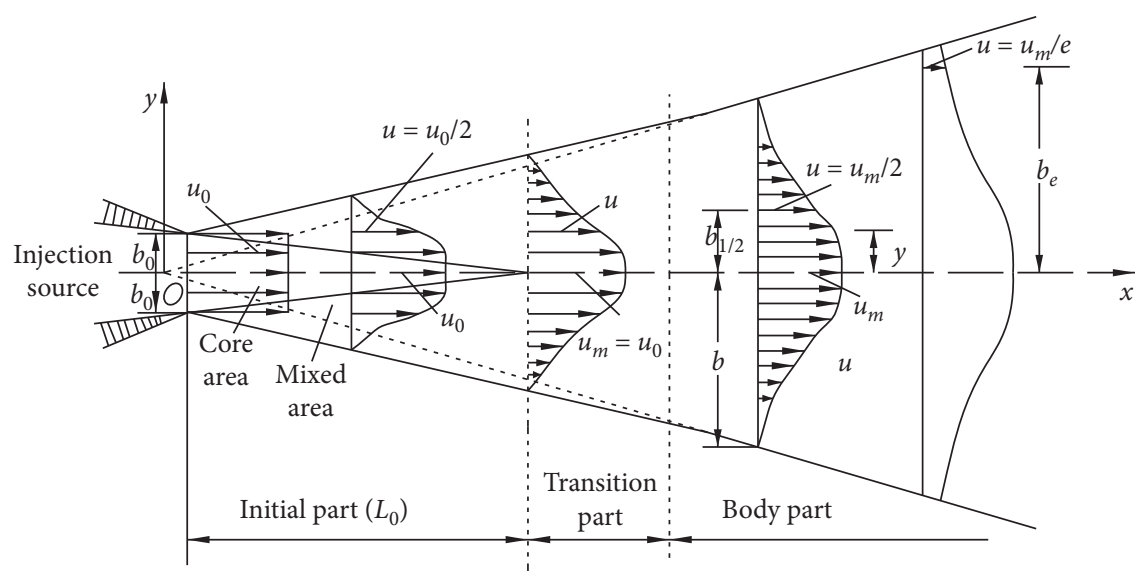

Figure 8: Calculation model of minimum dust removal airflow velocity [23]. $u_{m}$ : maximum average speed in the axial direction, m/s; $u_{0}$ : average speed of core area; $b$ : expanded thickness.

TABle 3: Average test data.

\begin{tabular}{|c|c|c|c|c|}
\hline Test item & Unit & Direction & Group 1 & Group 2 \\
\hline \multirow{2}{*}{ Exit slit width } & \multirow{2}{*}{$\mathrm{mm}$} & Upper & 12 & 20 \\
\hline & & Right & 9 & 15 \\
\hline \multirow{2}{*}{ Average airflow velocity at the injection outlet } & \multirow{2}{*}{$\mathrm{m} / \mathrm{s}$} & Upper & 18.2 & 17 \\
\hline & & Right & 14.65 & 10.4 \\
\hline \multirow{2}{*}{ Average airflow velocity at a distance of $1 \mathrm{~m}$ from the injection outlet ( $1 \mathrm{~m}$ above the base plate) } & \multirow{2}{*}{$\mathrm{m} / \mathrm{s}$} & Upper & 4.6 & 4.4 \\
\hline & & Right & 3.9 & 3.3 \\
\hline \multirow{2}{*}{ Average airflow velocity at a distance of $1.5 \mathrm{~m}$ from the injection outlet ( $1 \mathrm{~m}$ above the base plate) } & \multirow{2}{*}{$\mathrm{m} / \mathrm{s}$} & Upper & 2.9 & 3.4 \\
\hline & & Right & 3.2 & 2.78 \\
\hline
\end{tabular}

3.2. Dust Distribution in Roadway without ACDRD. According to "Coal Mine Safety Regulations," the airflow speed has the following regulations: the airflow speed of coal roadways and semicoal roadways during excavation is 0.25 to $4 \mathrm{~m} / \mathrm{s}$. In this study, dust concentration values were obtained at a relatively constant speed of $1.15 \mathrm{~m} / \mathrm{s}$. The dust concentration test results are shown in Figure 10. The measurement spot is the $X$-axis; the dust concentration and the respiratory dust ratio are the double $Y$ axis. 


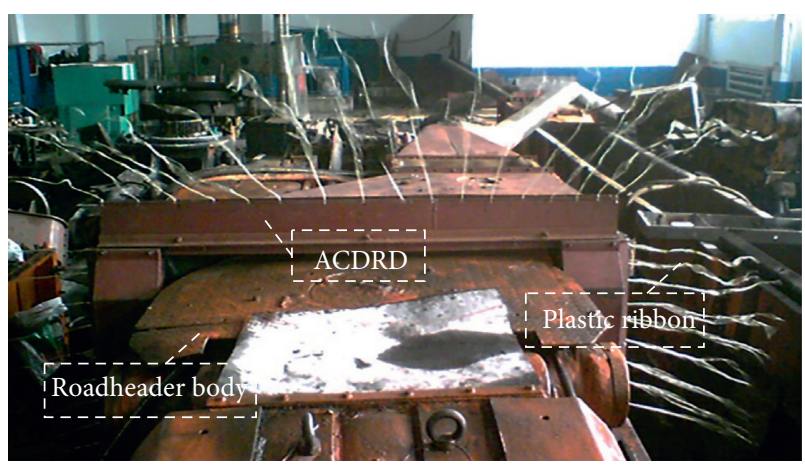

FIgURE 9: The location of the ACDRD on the roadheader.

Dust concentration at the front of the forcing fan is low and the dust forms a vortex on the other side of the fan, due to the blowing of fresh air. A narrow gap is formed between the roadway and the roadheader. A number of dust particles spread through the gap. As the air blows through narrow crevices, the airflow speed increases but the pressure decreases. The airflow creates a low-pressure zone, and then more dust particles are pressed into it. Through this narrow gap, dust particles move up and down from the middle of the roadway.

Within $40 \mathrm{~m}$, large particles settle rapidly and the total dust concentration drops rapidly. Most large particles stabilize after $40 \mathrm{~m}$. The fine dust is scattered in the roadway. The total dust concentration tends to stabilize.

Within $20 \mathrm{~m}$, the respiratory concentration drops sharply and is discharged under the effect of airflow. Within $20 \sim 40 \mathrm{~m}$, the airflow is very turbulent, and the exhaled dust is difficult to settle, so respiratory dust concentration decreases gradually. The respiratory dust spreads throughout the roadway, and the concentration tends to be stable after $40 \mathrm{~m}$. Respiratory dust is suspended in the air; it decreases relatively slowly by the total dust concentration.

The change in inhalable dust concentration is related to the change in total dust concentration. Due to the effect of air turbulence, the total dust concentration in the driver's work area is reduced. The first inflection point occurs because the large particles settle faster. After the large particle deposit is completed, the smaller particles of breathing dust become the main sediment and a second inflection point occurs. After that, the respiratory dust spreads to the roadway. The large particle dust continues to precipitate, with a third inflection point. With the continuous settlement of large particulate dust, the total dust concentration continues to decline, but the concentration of respiratory dust remains unchanged, and the curve begins to rise gradually. The curve changes gradually with the deposition of large particles after $90 \mathrm{~m}$.

The trend of total dust concentration and respirable dust concentration is almost the same. At a distance of $120 \mathrm{~m}$ from the heading face, the dust concentration in the roadway still does not meet the standards set out in the "Coal Mine Safety Regulations." Certain dust removal techniques should be used to improve the working environment.

3.3. Dust Removal Effect of ACDRD. The processing of the heading face has not changed, but the ACDRD is activated.

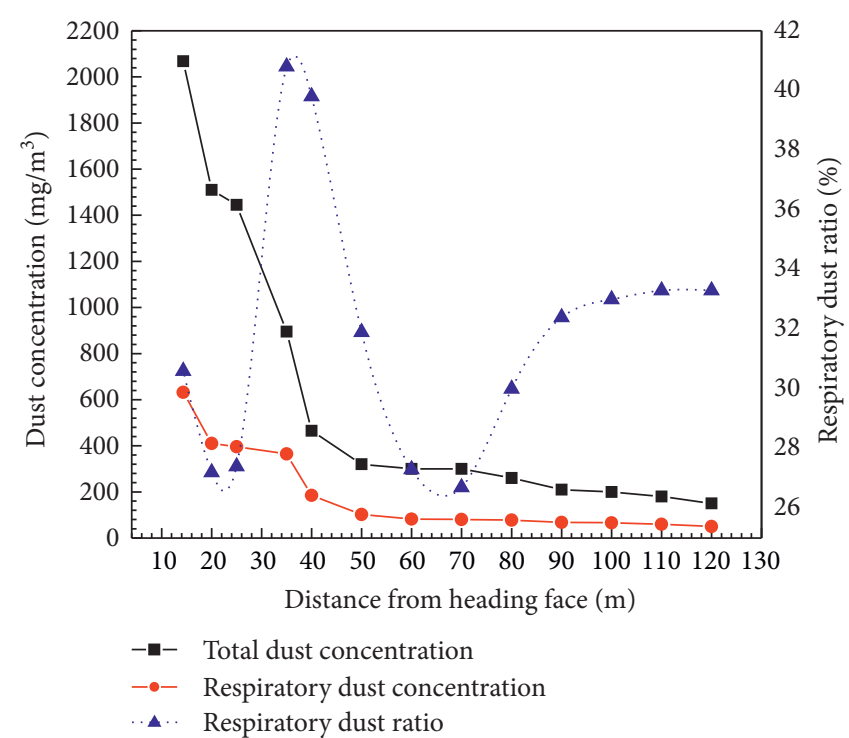

FIgURE 10: Distribution of dust concentration along the roadway.

The dust concentration distribution in the roadway was tested under the two conditions of $2.1 \mathrm{~m}$ and $3.0 \mathrm{~m}$ from the base plate. The results are shown in Figure 11.

The dust concentration in the working face has decreased due to the action of the exhaust fan. The vortex becomes smaller and moves toward the exhaust fan. The exhaust fan takes away a large number of dust particles.

When the position of the fan outlet is $2.1 \mathrm{~m}$ and $3.0 \mathrm{~m}$ from the base plate, the dust concentration in the aisle is of the same order of magnitude. The dust-proof effect of the fan at $2.1 \mathrm{~m}$ from the base plate is better than that at $3.0 \mathrm{~m}$.

According to the movement trajectory of the dust particles (as shown in Figure 12), it can be seen that part of the dust will be turned back after being injected by the air curtain. After installing the ACDRD, the dust concentration of the entire roadway is significantly reduced, indicating that the ACDRD has played its role. Some high-speed dust particles will spread through the air curtain to the entire roadway.

\section{Discussion}

The air curtain is generally used to regulate the airflow in the underground tunnel, and it is also used in the dust removal of the fully mechanized coal mining face. Although the theoretical results of ACDR for heading face have continuously emerged in the past few years, devices that can be used on workplace are relatively rare. Hao Wang had studied the principles and methods of air curtain isolation of respirable dust and successfully applied ACDR technology to rock tunnel's fully mechanized working face [17]. The ventilation method and space size of the heading face and the fully mechanized face are different, resulting in the ACDRD of the fully mechanized face not being used directly in tunneling. Baoshan Jia developed an ACDRD [26], but restricted by the technical safety of the equipment and the 


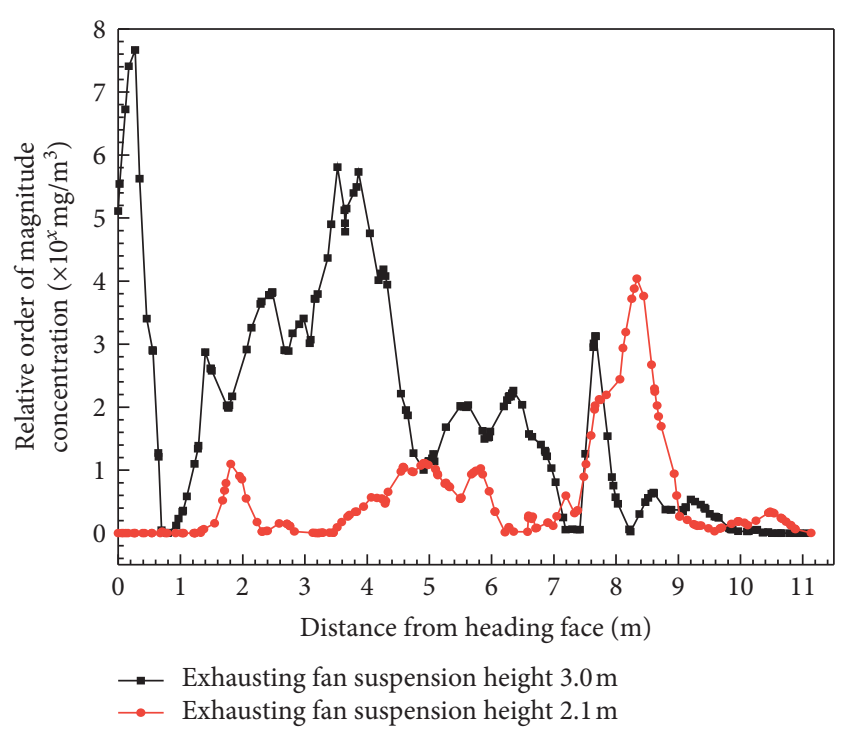

Figure 11: Comparison of the dust concentration.

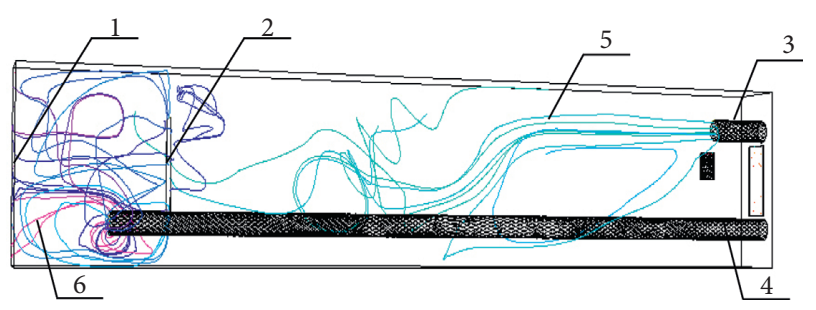

FIGURE 12: Schematic diagram of dust removal effect of ACDRD. (1) Heading face; (2) air curtain; (3) forcing ventilation; (4) exhaust ventilation; (5) fresh air; (6) exhaust air.

dust exhaust system, the equipment could not be massproduced and widely promoted. Professor Li proposed a comprehensive digging dust prevention method for dust collection by long-pressure and short-exhaust ventilation systems and built an ACDRD [10]. After the air curtain equipment is added to the fully mechanized roadway, it is not conducive to the work of the driver and also causes inconvenience to the on-site construction management.

The $\cap$-type jet device and jet box were developed in this article form an organic whole, and the device occupies a small space. When the placement position is appropriate, it basically does not affect the operation of the roadheader driver. In addition, the ACDRD proposed in this paper is based on dry dust collection. Without changing the original tunneling ventilation system, the application of the principle of ACDR can achieve the effect of suppressing the spread of dust.

Affected by machining accuracy, the actual size of ACDRD is slightly different from the design size. There is a certain deviation in the coupling degree with the roadheader. At the same time, the entire air curtain dust removal device has a certain air leakage. In practical applications, the equipment needs to be modified and reinforced to reduce air leakage and improve the dust removal effect.

\section{Conclusions}

(1) Using the principle of flat free turbulence injection, the axial maximum speed attenuation coefficients $k_{2}$ on the left and right sides are 4.25 and 3.63; the airflow velocity attenuation of the ACDRD at the upper, left, and right outlets of the " $\cap$ " slit is $17.39 \mathrm{~m} /$ s, $12.04 \mathrm{~m} / \mathrm{s}$, and $13.66 \mathrm{~m} / \mathrm{s}$, respectively; the $\mathrm{mini}-$ mum airflow velocity of the air curtain is $5.48 \mathrm{~m} / \mathrm{s}$; and the airflow quantity of the ACDRD is $149.4 \mathrm{~m}^{3} /$ $\min$.

(2) The total dust concentration is the highest in the operator's operation of the roadheader; the farther away the heading face, the lower the total dust concentration. A narrow gap is formed between the roadway and the roadheader, and a number of dust particles spread through the gap between the roadheader and the walls.

(3) The trend of total dust concentration and respirable dust concentration is almost the same. Within $20 \mathrm{~m}$, the respiratory concentration drops sharply and is discharged under the effect of airflow. The relative total dust concentration decreased slowly. Within $20 \sim 40 \mathrm{~m}$, the airflow is very turbulent, and the exhaled dust is difficult to settle, so respiratory dust concentration decreases gradually. The respiratory dust spreads throughout the roadway and the concentration tends to be stable after $40 \mathrm{~m}$. Respiratory dust is suspended in the air; it decreases relatively slowly by the total dust concentration.

(4) When the airflow outlet of exhaust fan is $2.1 \mathrm{~m}$ away from the base plate, the dust removal effect is better than that at $3.0 \mathrm{~m}$ from the base plate.

\section{Data Availability}

The data used to support the findings of this study are included within the article.

\section{Conflicts of Interest}

The author declares no conflicts of interest regarding the publication of this paper.

\section{Acknowledgments}

This research was funded by the National Natural Science Foundation of China (NSFC), under grant number 51774168 .

\section{References}

[1] J. Zhang, K. Xu, G. Reniers, and G. You, "Statistical analysis the characteristics of extraordinarily severe coal mine accidents (ESCMAs) in China from 1950 to 2018," Process Safety and Environmental Protection, vol. 133, pp. 332-340, 2020.

[2] P. Cai, W. Nie, D. Chen, S. Yang, and Z. Liu, "Effect of air flowrate on pollutant dispersion pattern of coal dust particles at fully mechanized mining face based on numerical simulation," Fuel, vol. 239, pp. 623-635, 2019. 
[3] X. Huang, Y. Li, and S. Chen, "Effectiveness of drilling ventilation on heading face in long-distance tunneling," Environmental Engineering and Management Journal, vol. 18, no. 12, pp. 2739-2746, 2019.

[4] S. A. o. W. Safety, Coal Mine Safety Regulations China, Coal Industry Press, Beijing, China, 2016.

[5] K. J. Candra, S. A. Pulung, and M. A. Sadashiv, "Dust dispersion and management in underground mining faces," International Journal of Mining Science and Technology, vol. 24, no. 1, pp. 39-44, 2014.

[6] J. Longzhe, Dust Control Technology, Coal Industry Press, Beijing, China, 1993.

[7] H. Wang, S. Shi, R. Liu et al., "Research on dust-isolation of air curtain and its application to comprehensive mechanized working face," Journal of Xiangtan Mining Institute, vol. 14, pp. 11-15, 1999.

[8] X. Song, "Application of forced-out air curtain ventilation in tunnel construction," Physica A: Statistical Mechanics and its Applications, vol. 50, no. 2, pp. 173-180, 2013.

[9] H. Wang, S. Shi, R. Liu, and H. Liu, "Research and application of dust isolation technology at drivers position in fullymechanized coal face," Journal of China Coal Society, vol. 25, no. 2, pp. 176-179, 2000.

[10] Y. Li and J. Liu, "Numerical simulation of dust control using air curtain based on gas-solid two-phase flow," Journal of Liaoning Technical University, vol. 5, 2012.

[11] Q. Liu, W. Nie, Y. Hua, H. Peng, C. Liu, and C. Wei, "Research on tunnel ventilation systems: dust diffusion and pollution behaviour by air curtains based on CFD technology and field measurement," Building and Environment, vol. 147, pp. 444-460, 2019.

[12] Q. Liu, W. Nie, Y. Hua, H. Peng, and Z. Liu, "The effects of the installation position of a multi-radial swirling air-curtain generator on dust diffusion and pollution rules in a fullymechanized excavation face: a case study," Powder Technology, vol. 329, pp. 371-385, 2018.

[13] Q. Liu, W. Nie, Y. Hua et al., "Long-duct forced and shortduct exhaust ventilation system in tunnels: formation and dust control analysis of pressure ventilation air curtain," Process Safety and Environmental Protection, vol. 132, pp. 367-377, 2019.

[14] W. Nie, W.-M. Cheng, Y.-B. Yu, J. Xie, W. Liu, and S. Cao, "The research and application on whole-rock mechanized excavation face of pressure ventilation air curtain closed dust removal system," Meitan Xuebao/Journal of the China Coal Society, vol. 37, no. 7, pp. 1165-1170, 2012.

[15] N. Wen, L. Yanghao, W. Wenle, H. Xiangming, M. Xiao, and P. Huitian, "Effect of suppressing dust by multi-direction whirling air curtain on fully mechanized mining face," International Journal of Mining Science and Technology, vol. 26, no. 4, pp. 629-635, 2016.

[16] W. Nie, W. Wei, P. Cai et al., "Simulation experiments on the controllability of dust diffusion by means of multi-radial vortex airflow," Advanced Powder Technology, vol. 29, no. 3, pp. 835-847, 2018.

[17] H. Wang, W. Nie, W. Cheng, Q. Liu, and H. Jin, "Effects of air volume ratio parameters on air curtain dust suppression in a rock tunnel's fully-mechanized working face," Advanced Powder Technology, vol. 29, no. 2, pp. 230-244, 2018.

[18] H. Wang, W. Cheng, B. Sun, and Y. Ma, "Effects of radial air flow quantity and location of an air curtain generator on dust pollution control at fully mechanized working face," Advanced Powder Technology, vol. 28, no. 7, pp. 1780-1791, 2017.
[19] Ministry of Health of the People's Republic of China, Sampling Specifications for the Monitoring of Hazardous Substances in the Air of Workplaces, Ministry of Health of the People's Republic of China, Beijing, China, 2004.

[20] Ministry of Health of the People's Republic of China, Determination of Dust Concentration and Dispersion, Ministry of Health of the People's Republic of China, Beijing, China, 1984.

[21] Ministry of Health of the People's Republic of China, Determination of Dust in the Air of Workplace Part One: Total Dust Concentration, Ministry of Health of the People's Republic of China, Beijing, China, 2007.

[22] Ministry of Health of the People's Republic of China, Determination of Dust in the Air of Workplace Part Two: Respiratory Dust Concentration, Ministry of Health of the People's Republic of China, Beijing, China, 2007.

[23] L. Peiqing, Free Turbulent Jet Theory, Beijing University of Aeronautics and Astronautics Press, Beijing, China, 2008.

[24] M. Albertson and Y. B. Dai, R. A. Jensen and H. Rouse, "Diffusion of submerged jets," American Society of Civil Engineers ASCE Library, vol. 115, no. 1, pp. 639-664, 1950.

[25] G. Abraham, Jet Diffusion in Stagnant Ambient Fluid, TU Delft Faculty of Civil Engineering and Geosciences, Delft, Netherlands, 1963.

[26] B. Jia, W. Wang, Y. Qi, Y. Liu, and S. Li, "Experiment study and design on dust removal system in air curtain dust collector of mine roadway heading face," Coal Science and Technology, vol. 46, no. 4, pp. 141-145, 2018. 